\title{
Effects of extremely low frequency electromagnetic fields on morphine analgesia and tolerance in rats
}

\author{
Ercan Ozdemir ${ }^{1}$, Ayse Demirkazik ${ }^{2}$, Sinan Gursoy ${ }^{3}$, Ahmet S. Taskıran ${ }^{1}$, Olca Kilinc ${ }^{2}$ \\ and Gokhan Arslan ${ }^{1}$ \\ ${ }^{1}$ Departments of Physiology, School of Medicine, Cumhuriyet University, Sivas, Turkey \\ ${ }^{2}$ Departments of Biophysics, School of Medicine, Cumhuriyet University, Sivas, Turkey \\ ${ }^{3}$ Departments of Anesthesiology and Reanimation Cumhuriyet, University School of Medicine, Sivas, Turkey
}

\begin{abstract}
Several studies have demonstrated that the electromagnetic fields produce analgesic activity. The aim of this study was to investigate the effects of extremely low frequency (ELF) electromagnetic fields (EMF) on morphine analgesia and tolerance in rats. In the study, 78 adult male Wistar albino rats (approximately $240 \pm 12 \mathrm{~g}$ ) were used. The application of $50 \mathrm{~Hz}$ magnetic field, each day the same times for 30 minutes for 15 days, and a total of four times every 15 minute intervals. To constitute morphine tolerance, high dose of morphine $(50 \mathrm{mg} / \mathrm{kg}$ ) were administered for 3 days in rats and tolerance was evaluated on day 4. Prior to analgesia tests, the effective dose $(5 \mathrm{mg} / \mathrm{kg})$ of morphine was injected into rats. In the statistical analyzes of the data, analysis of variance (two-way ANOVA) was used and the multiple comparison determined by Tukey tests. The maximum analgesic effect of the $5 \mathrm{mT}$ magnetic field was determined on 7 days. Administration of morphine (5 mg/ $\mathrm{kg}$ ) in rats exposed to a magnetic field, the analgesic effect was significantly higher compared to the morphine group $(p<0.05)$. Morphine tolerant animals exposed to a magnetic field, the analgesic effect was found significantly higher than morphine tolerant group rats $(p<0.05)$. Analgesia test data demonstrated that application of ELF-EMFs to rats increases the morphine analgesia and reduces morphine tolerance.
\end{abstract}

Key words: Electromagnetic field - Analgesia - Morphine - Morphine tolerance - Analgesia tests

\section{Introduction}

Morphine, an opioids drug, is a clinical highly effective treatment for patients with severe and chronic pain. Nevertheless, the chronic use of morphine is limited by the potential for adverse effects, addiction and the development of morphine tolerance (Dumas and Pollack 2008; Morgan and Cristie 2011). The mechanisms of morphine antinociceptive tolerance are complex and not fully understood. Proposed mechanisms for opioid analgesic tolerance comprise desensitization of opioid receptors, induction of alpha-2 noradrenergic and serotonergic systems, inhibition of dopamine and cannabinoid receptors, and altered intracellular signaling pathways, including nitric oxide and

Correspondence to: Ercan Ozdemir, Department of Physiology, School of Medicine, Cumhuriyet University, 58140 Sivas, Turkey E-mail: ercan_ozdemir@hotmail.com protein kinase C (Nestler and Aghajanian 1997; Gursoy et al. 2011; Ozdemir et al. 2011, 2013; Altun et al. 2015).

Extremely low frequency (ELF) electromagnetic field (EMF) has been shown to have a variety of biological effects and induce many different types of cellular changes (Sienkiewicz et al. 2005). EMF has been used for its analgesic efficacy for several decades. EMF therapy has verified to be a safe, simple and non-invasive method to treat different types of pain or inflammation (Fernandez et al. 2007). The pulsed magnetic fields stimulate small electrical currents in the tissues because of the often changing magnetic influx. It has been proposed that these currents are the mechanism underlying the alleged analgesia associated with magnetic field therapy (Basset 1993). Several studies suggest that therapeutic applications of EMF at a very low frequency level $(1-100 \mathrm{~Hz})$ induce the immune system by repressing inflammatory responses in the cell-membrane (Ross and Harrison 2013). It has also been demonstrated that they cause induc- 
tion of nerve transmission, vasodilatation, enhanced tissue repair, and reduction of edema (Ramey 1998; Trock 2000).

Clinical studies report, EMF passes through the skin into the conductive tissue, decreasing nociception and the edema shortly after trauma (Traina et al. 1998; Chalidis et al. 2011). The low frequency pulsed EMF therapy (0.1 to 64 $\mathrm{Hz}$ ) improve mobility, decrease pain and fatigue in patients with fibromyalgia (Sutbeyaz et al. 2009). The experimental studies indicate that EMF is effective in the treatment of pain and inflammation in patients with osteoarthritis (Pilla et al. 2013; Sadoghi et al. 2013), without the unwanted effects of opioids. Some evidence suggests that administration of cytokine antagonists attenuates the development of analgesic tolerance and prevents the hyperalgesia in response to systemic morphine (Song and Zhao 2001). Furthermore, it has been reported that the EMF has an anti-inflammatory effect by reducing proinflammatory cytokines (Pesce et al. 2013). EMF exposure $(60 \mathrm{~Hz}, 0.3 \mathrm{mT})$ amplifies TGF- $\beta$ signaling and increases the generation of specific $\mathrm{T}$ cell subsets (Lee et al. 2016).

The neural pathways involved in the effects of EMF on pain have not been exactly understood. The nociceptive perception is the result of complicated interaction between the primary pain ascending pathways connecting spinal cord and midbrain pain centres, and descending regulatory pathways (Fields 2004). Animal studies suggest that the analgesic effects of EMF are centrally integrated in the hot-plate test (Kieffer 1999). In this way, the EMF-induced decrease of pain sensations probably reflect supra spinal analgesia.

Numerous studies have indicated that EMFs reduce morphine-induced analgesia. For instance, Kavaliers and Ossenkopp (1988) determined that 15-30 min exposures to magnetic field $(0.1-0.8 \mathrm{mT} ; 0.5 \mathrm{~Hz})$ inhibited analgesia from opioid agonists in land snails. Accordingly, exposing the snails to $0.1 \mathrm{mT}, 60 \mathrm{~Hz}$ magnetic fields produced similar results, with decreased opioid-induced analgesia. In addition, acute exposure to a variety of magnetic field conditions has been found to inhibit the analgesic and locomotor effects of morphine in mice (Ossenkopp and Kavaliers 1988) and magnetic fields abolish the enhanced nocturnal analgesic response to morphine (Kavaliers et al. 1984). The inhibition of nocturnal morphine analgesia is a function of magnetic field intensity in mice (Ossenkopp and Kavaliers 1988). Furthermore, a study on the land snail Cepaea nemoralis has shown that the electromagnetic field reduces opioidinduced analgesia. Conversely, Thomas et al. (1997a) suggest that 15 -min exposures to an EMF $(100 \mu \mathrm{T})$ increase opioid induced-analgesia in land snails. Injection of naloxone, an opioid antagonist, resulted in a decreased, but not completely removed antinociceptive effects of EMF. These findings indicate the analgesic action of a specific EMF via an endogenous opioid mechanism. The ability of naloxone to decrease, but not fully removed the antinociceptive effect of EMF shows the presence of at least partially $\delta$-opioid receptor mediation (Thomas et al. 1997b).

Therapeutic uses of magnetic field exposure include a component of pain reduction; however, there are controversial reports in the literature regarding the effects of magnetic field exposure on the opioid analgesia. In light of these data, the aim of the current study was to investigate the effects of ELF-EMF on morphine analgesia and tolerance in rats.

\section{Materials and Methods}

\section{Animals}

This study was conducted at Cumhuriyet University Experimental Research Center with the permission granted by Local Animal Studies Ethical Board (CUHEK/2014-67). A total of 78 adult male Wistar albino rats (weighing 240 $\pm 12 \mathrm{~g}$ ) were used in this study. The rats were housed four per cage in a room maintained at $21 \pm 2{ }^{\circ} \mathrm{C}$ with an alternating $12 \mathrm{~h}$ dark/12 $\mathrm{h}$ light cycles and free access to water and food. Experimental animals were acclimatized to laboratory conditions before the analgesia tests. All experiments were carried out blindly between 10:00 and 17:00 h.

\section{Induction of morphine tolerance}

The experimental animals were rendered tolerant to morphine using the method by a previous study on the induction of morphine analgesic tolerance (Zarrindast et al. 2002). To constitute morphine tolerance, it was used a 3-day cumulative dosing regimen. The treatment schedule consisted of twice daily s.c. doses of morphine given at $30 \mathrm{mg} / \mathrm{kg}$ (a.m.) and $45 \mathrm{mg} / \mathrm{kg}$ (p.m.) on day 1; 60 and $90 \mathrm{mg} / \mathrm{kg}$ on day 2 ; and $120 \mathrm{mg} / \mathrm{kg}$ twice on day 3 . Animals were assessed for tolerance on the 4 th day. The tail-flick (TF) and hot-plate (HP) tests were done for each rat to average them as a baseline latency; then the challenge dose of morphine ( $5 \mathrm{mg} / \mathrm{kg}$; s.c.) was injected; $30 \mathrm{~min}$ after morphine injection other the tail-flick and hot-plate tests were done to average them to find post-drug latency for each rat for evaluating the development of morphine tolerance.

\section{Antinociceptive tests}

To evaluate thermal nociception, it was used a standardized TF test (May TF 0703 Tail-flick Unit, Commat) and HP test (May AHP 0603 Analgesic Hotplate Commat, Turkey). In the TF test, the radiant heat source was focused on the distal portion of the tail at $3 \mathrm{~cm}$ after administration of the vehicle and study drugs. Following vehicle or compound administration, tail-flick latencies (TFL) were obtained. The infrared intensity was adjusted so that basal TFL occurred at $2.9 \pm 0.5 \mathrm{~s}$. 
Animals with a baseline TFL below 2.4 or above $3.4 \mathrm{~s}$ were excluded from further testing. The cutoff latency was set at $15 \mathrm{~s}$ to avoid tissue damage. Any animal not responding after $15 \mathrm{~s}$ was excluded from the study. The analgesic response is usually attributed to central mechanisms in this test (Ramabadran et al. 1989; Kanaan et al. 1996).

In the HP test, the rats were individually placed on the $\mathrm{HP}$ with the temperature adjusted to $55 \pm 0.5^{\circ} \mathrm{C}$. The latency to the first sign of paw licking or jump response to avoid the heat was taken as an index of the pain threshold; the cut-off time was $30 \mathrm{~s}$ in order to avoid damage to the paws. The antinociceptive response on the HP test is considered to result from a combination of peripheral and central mechanisms (Kanaan et al. 1996).

\section{Electromagnetic field exposure conditions}

The EMF exposure system consists of 4 sections: 1 . computer, 2. power supply, 3. digital teslameter (Phywe, 80010), 4. solenoid with animal cage (Figure 1). Before the EMF treatment, all rats were acclimated to their environment for 1 week. Habituation to the treatment conditions was accomplished by placing the rats in the animal cage at least three times for $30 \mathrm{~min}$. The animals were subjected to repeated exposures of alternating $50 \mathrm{~Hz}$ EMF for 15 days. It was performed in three different magnetic field strengths (1, 5 and $10 \mathrm{mT})$. Thus, the EMF applied corresponded, according to the extensively used classification, to an extremely low-frequency range of the electromagnetic phenomena. The EMF was generated in a specially designed solenoid (500 $\mathrm{mm}$ in length and $210 \mathrm{~mm}$ in diameter, 1400 turns of insulated $1.4 \mathrm{~mm}$ copper wire). Electrical current $(50 \mathrm{~Hz}, 220 \mathrm{~V})$ was passed through the device (having a time relay). The alternating EMF was exposed to the rats for four 30-min episodes halted by 15-min intervals; thus, the entire EMF sessions carried out at the same time period (9.00-11.00 a.m.) lasted 165 min every day. The EMF intensity in the solenoid was measured by a digital tesla meter with an axial probe. The solenoid was always kept in a north-south direction, and its temperature was maintained constant at $22.0 \pm 2{ }^{\circ} \mathrm{C}$. The plexiglass rat cage $(40 \times 17 \times 13 \mathrm{~cm}$ in dimensions) was placed in the solenoid. Three rats were simultaneously placed in the cage to be exposed to EMF. The control group rats were also placed in the animal cage, but they were not exposed to EMF. Food and water were provided ad libitum in this animal cage.

\section{Experimental protocols}

Except the control, all group animals were exposed to a magnetic field for 15 days. Analgesic assays were performed on selected days for 15 days $(1,4,7,11$, and 15 days). The rats were subjected to TF and HP tests on the same day. The analgesic test method of rats in each group was randomly assigned to prevent carry over effects. The antinociceptive effects of three different EMF strengths $(1,5$ and $10 \mathrm{mT})$ were considered at 30 -min intervals $(0$, $30,60,90$, and $120 \mathrm{~min})$ by TF and HP test in rats $(n=6)$. Initially, the maximum analgesic effect of EMF was detected in 15 days. Subsequently, the effects of the magnetic field were determined on morphine analgesia and tolerance by TF and HP test.

\section{Data analysis}

In order to calculate percentage of maximal antinociceptive effects (\% MPE), lick/escape latencies (HP) and tail-withdrawal latencies (TF) were converted to percent antinociceptive effect using the following equation:

$\% \mathrm{MPE}=[($ test latency - baseline $) /($ cutoff-baseline $)] \times 100$

\section{Statistical analysis}

The data (\% MPE) were analyzed by two-way analysis of variance (ANOVA) and repeated measures ANOVA followed by a Tukey post hoc test for multiple comparisons between groups (SPSS 20.0 for windows). All data are presented as means \pm S.E.M. The level of significance was set at $p<0.05$.

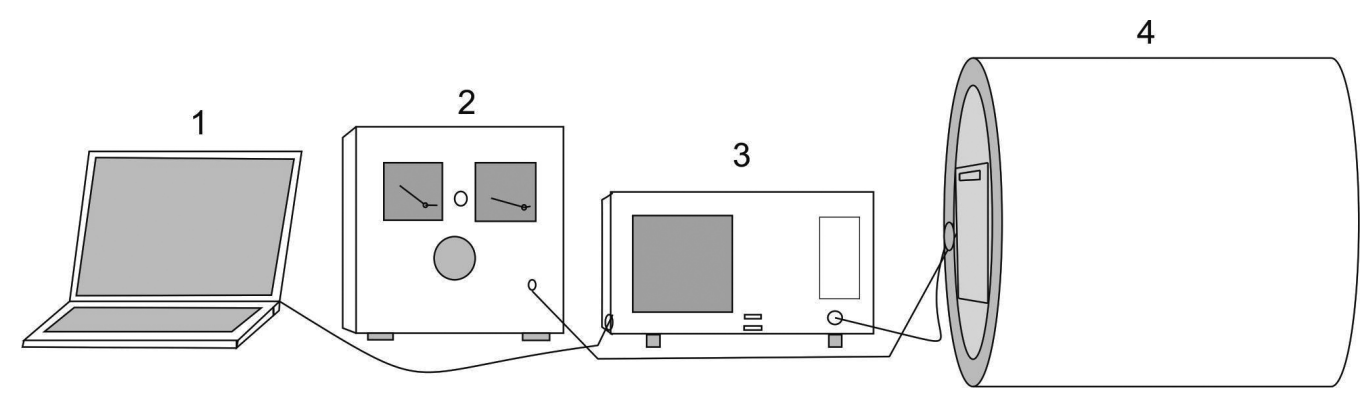

Figure 1. The EMF exposure system. 1, computer; 2, power supply; 3, digital Teslameter (Phywe, 80010); 4, solenoid with animal cage. 


\section{Results}

Analgesic effects of three different EMF strengths $(1,5$ and $10 \mathrm{mT})$

The maximal analgesic effect of the magnetic field was observed on day 7 in all group rats (1, 5 and $10 \mathrm{mT}$ ) (Fig. 2). The analgesic activity of magnetic field $1 \mathrm{mT}$ (TF: $13.66 \pm$ 127 and HP: $28.95 \pm 3.10$ ), $5 \mathrm{mT}$ (TF: $25.89 \pm 3.00$ and HP: $61.73 \pm 2.95)$ and $10 \mathrm{mT}$ (TF: $25.37 \pm 2.41$ and HP: $53.85 \pm$ 4.62) groups were significantly higher than control group rats $\left(\mathrm{F}_{3,20}=23.13, p<0.05\right.$ for $\mathrm{TF}$ and $\mathrm{F}_{3,20}=50.46, p<0.01$ for $\mathrm{HP})$. The maximal analgesic effect was determined at $5 \mathrm{mT}$ group and 90 min measurement (TF: $35.13 \pm 2.63$ and HP: $65.73 \pm 2.92)$ for three different magnetic field strength $\left(F_{3,20}\right.$ $=555.51$ for $\mathrm{TF}$ and $\mathrm{F}_{3,20}=766.03$ for $\mathrm{HP}, p<0.001$; Fig. 3 ).

A

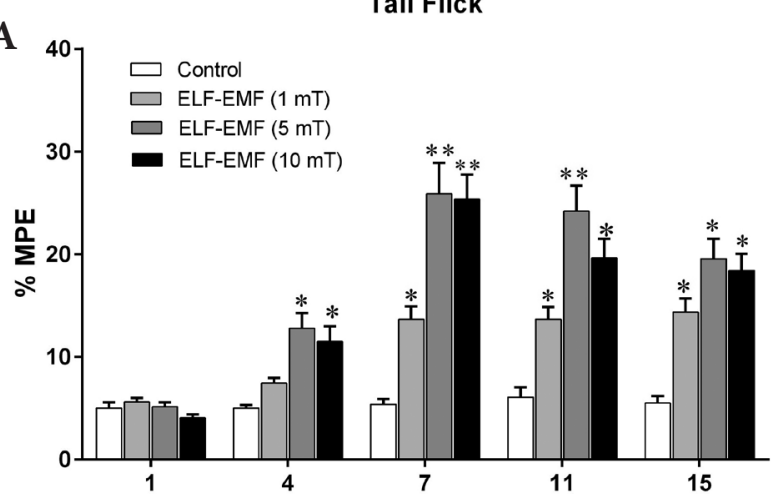

B

Hot Plate

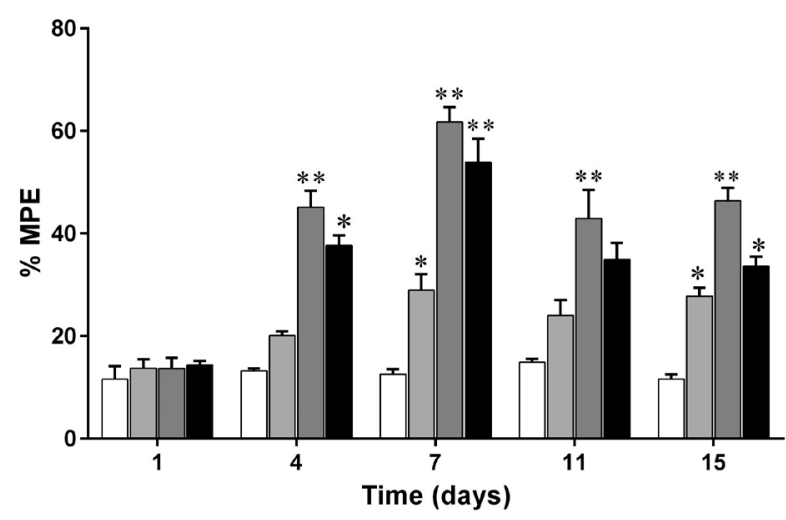

Figure 2. Analgesic effects of three different EMF strengths (1, 5, 10 $\mathrm{mT}$ ) on rats measured by tail-flick test (A) and hot-plate test (B). The maximal analgesic effect of the magnetic field was observed on day 7 in all groups of rats: ELF-EMF $(1 \mathrm{mT}),(5 \mathrm{mT})$ and $(10 \mathrm{mT})$. The analgesic activity of magnetic field 1,5 and $10 \mathrm{mT}$ were significantly higher than control group rats $(p<0.01)$. Each point represents the mean \pm SEM of $\%$ MPE for 6 rats. ELF-EMF, extremely low-frequency electromagnetic fields; \% MPE, percentage of maximal antinociceptive effects. ${ }^{*} p<0.01$ compared to the control, ${ }^{* *} p<0.05$ compared to $1 \mathrm{mT}$ group.

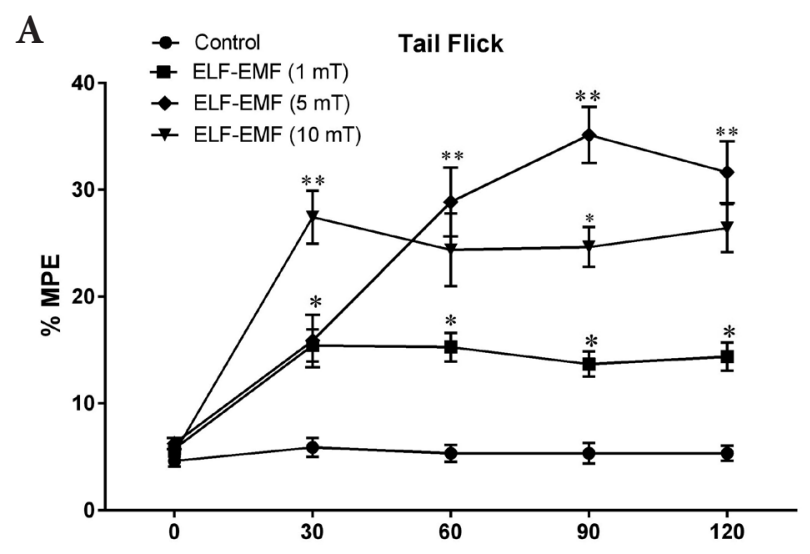

B

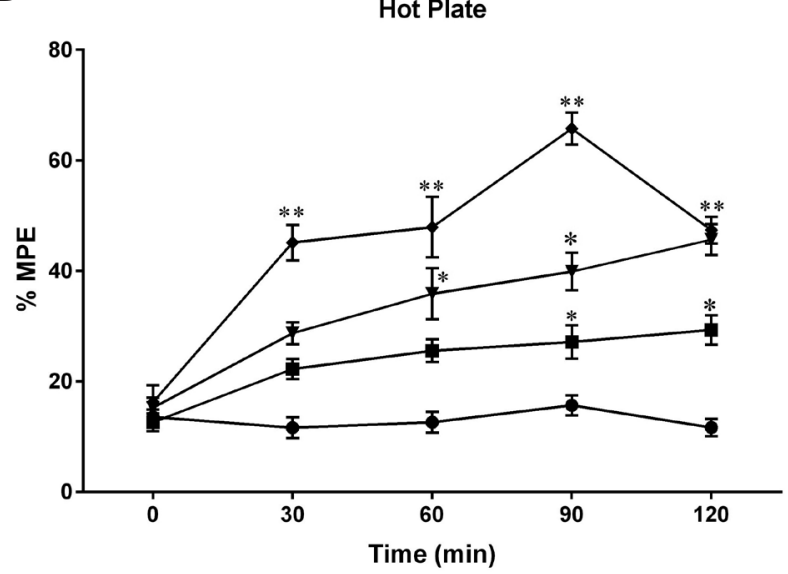

Figure 3. Time-dependent change of EMF analgesic effects. The effect of EMF in the tail-flick (A) and hot-plate test (B). The maximal analgesic effect was determined at $5 \mathrm{mT}$ group and $90 \mathrm{~min}$ measurement for three different magnetic field strength. Each point represents the mean \pm SEM of $\%$ MPE for 6 rats. ELF-EMF, extremely low frequency- electromagnetic fields. ${ }^{\star} p<0.01 \mathrm{com}$ pared to the control, ${ }^{* *} p<0.05$ compared to $1 \mathrm{mT}$ group. (For abbreviations see Fig. 2).

\section{Effect of EMF on morphine analgesia}

Obtained data suggested that the exposure EMF to the rats (5 mT; TF: 34.083 .44 and HP: $62.04 \pm 4.89$ ) and administration of morphine $(5 \mathrm{mg} / \mathrm{kg}$; TF: $61.09 \pm 5.47$ and HP: $69.65 \pm 4.82)$ produce a significant increase in $\% \mathrm{MPE}$ in both the TF ( $p<0.05$; Fig. $4 \mathrm{~A})$ and HP $(p<0.05$; Fig. $4 \mathrm{~B})$ assays as compared to saline group rats (TF: $6.98 \pm 0.93$ and HP: $15.64 \pm 1.23$ ). The analgesic activity of morphine (TF: $61.09 \pm 5.47$ and HP: $69.65 \pm 4.82$ ) is significantly increased by the exposure EMF to the rats (TF: $72.32 \pm 5.08$ and HP: $85.43 \pm 5.54)$ at $60 \mathrm{~min}$ measurements $\left(\mathrm{F}_{3,20}=424.98\right.$ for $\mathrm{TF}$ and $\mathrm{F}_{3,20}=380.47$ for HP, $\left.p<0.05\right)$. 


\section{Effect of EMF on morphine tolerance}

Statistical analysis indicated that the exposure magnetic field to morphine tolerant rats (TF: $39.66 \pm 3.49$ and HP: $69.08 \pm 4.56$ ) was a significant increase in \% MPE (decrease morphine tolerance) as compared to the morphine tolerant groups (TF: $29.23 \pm 3.02$ and HP: $42.67 \pm 4.58)\left(\mathrm{F}_{3,20}=\right.$ 116.96 for TF and $\mathrm{F}_{3,20}=277.38$ for HP, $p<0.05$; Fig. 5). In addition, the maximum analgesic effect was determined at 60 min measurements in TF and HP tests.

\section{The analgesic effects of different doses of morphine}

To determine the effective morphine dose, we measured the antinociceptive responses for the 3 different doses of morphine $(2.5,5$, and $10 \mathrm{mg} / \mathrm{kg}$; s.c.) at $30 \mathrm{~min}$ intervals

\section{A}

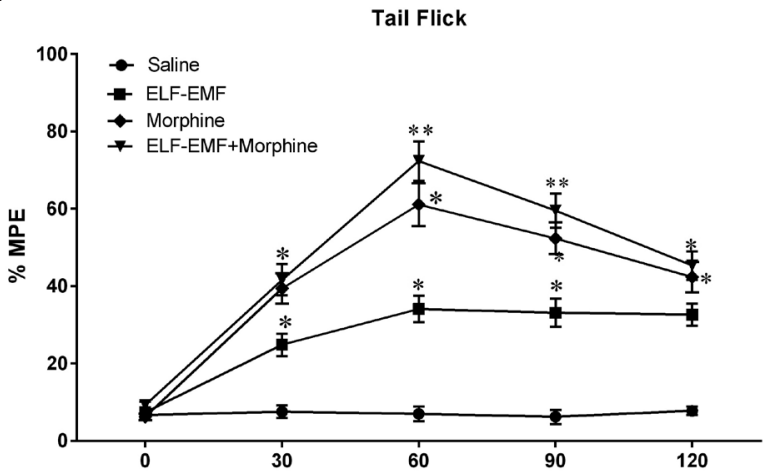

B

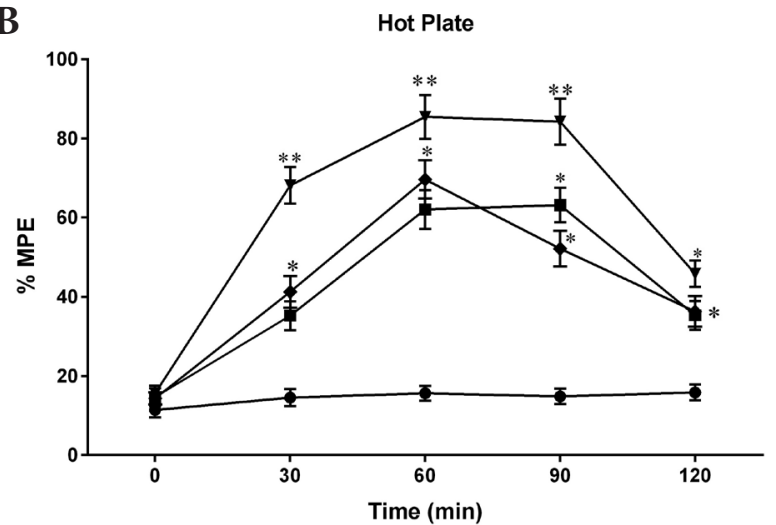

Figure 4. Effect of EMF on morphine analgesia. The effect of EMF in the tail-flick (A) and hot-plate test (B). The exposure EMF to the rats and administration of morphine produce a significant increase in \% MPE in both the tail-flick and hot-plate assays as compared to saline group rats The analgesic activity of morphine is significantly increased by the exposure EMF to the rats at $60 \mathrm{~min}$ measurements. Each point represents the mean \pm SEM of $\%$ MPE for 6 rats. ${ }^{*} p<$ 0.01 compared to the saline and ${ }^{* *} p<0.05$ compared to morphinetreated group. (For abbreviations see Fig. 2).
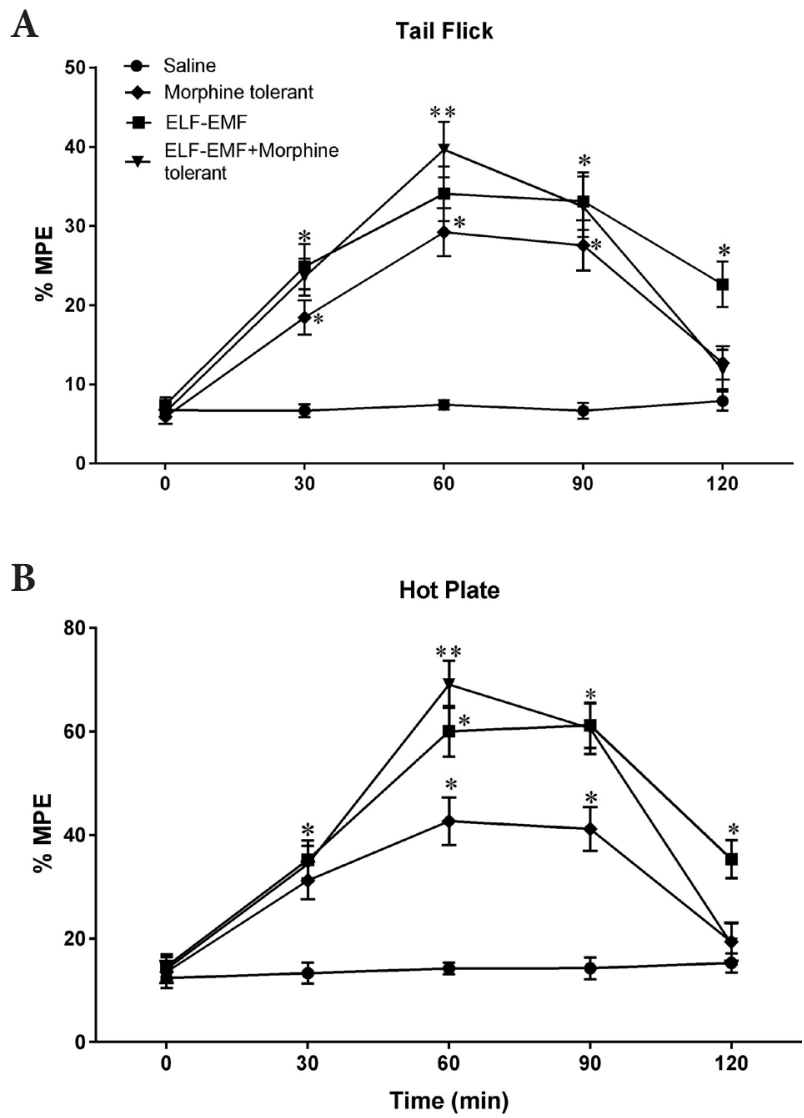

Figure 5. Effect of EMF on morphine tolerance. The effect of EMF in the tail-flick (A) and hot-plate test (B). The exposure EMF to morphine tolerant rats was a significant increase in $\%$ MPE (decrease morphine tolerance) as compared to the morphine-tolerant groups. Each point represents the mean \pm SEM of $\%$ MPE for 6 rats. ${ }^{*} p<0.05$ compared to the saline and ${ }^{* *} p<0.05$ compared to morphine-tolerant rats. (For abbreviations see Fig. 2).

by TF and HP test. The maximum \% MPE was observed at $60 \mathrm{~min}$ after administration of a $5 \mathrm{mg} / \mathrm{kg}$ dose of morphine $(63.09 \pm 5.47$ for the TF and $69.65 \pm 4.82$ for the HP test; Table 1). The \% MPE produced by morphine $(5 \mathrm{mg} / \mathrm{kg}$ ) was significantly higher than in the other groups in both the TF and $\mathrm{HP}$ tests in rats $\left(\mathrm{F}_{3,20}=220.08\right.$ for TF and $\mathrm{F}_{3,20}=180.51$ for HP, $p<0.01)$.

\section{Discussion}

A substantial number of studies indicate that exposure to EMF affects pain sensitivity (nociception) and pain inhibition (analgesia). More prolonged exposure to EMF usually resulted in increase in pain sensitivity. For example, continuous exposures to an EMF for more than 2 hours and up to 
Table 1. The antinociceptive effects of different doses of morphine

\begin{tabular}{|c|c|c|c|c|c|c|}
\hline & & \multicolumn{5}{|c|}{ Time (min) } \\
\hline & & 0 & 30 & 60 & 90 & 120 \\
\hline \multicolumn{7}{|l|}{ Tail-flick } \\
\hline \multirow[t]{2}{*}{ Saline } & & $6.55 \pm 0.92$ & $7.63 \pm 0.96$ & $8.47 \pm 1.02$ & $6.79 \pm 0.98$ & $5.99 \pm 0.88$ \\
\hline & 2.5 & $5.72 \pm 0.98$ & $34.60 \pm 1.90^{*}$ & $50.32 \pm 3.75^{\star}$ & $48.78 \pm 3.88^{*}$ & $34.38 \pm 2.87^{\star}$ \\
\hline \multirow[t]{2}{*}{ Morphine (mg/ml) } & 5 & $6.23 \pm 0.84$ & $39.42 \pm 3.95^{\star}$ & $63.09 \pm 5.47^{\star \star}$ & $54.34 \pm 4.12^{\star *}$ & $42.36 \pm 3.87^{\star}$ \\
\hline & 10 & $8.09 \pm 1.09$ & $45.56 \pm 4.09^{*}$ & $61.79 \pm 5.02^{\star *}$ & $57.38 \pm 3.95^{\star *}$ & $45.60 \pm 3.83^{*}$ \\
\hline \multicolumn{7}{|l|}{ Hot-plate } \\
\hline \multirow[t]{2}{*}{ Saline } & & $13.52 \pm 1.32$ & $12.42 \pm 1.13$ & $15.44 \pm 1.07$ & $11.62 \pm 1.08$ & $13.18 \pm 1.32$ \\
\hline & 2.5 & $12.89 \pm 1.23$ & $35.56 \pm 2.84^{*}$ & $54.45 \pm 4.15^{\star}$ & $37.50 \pm 3.22^{\star}$ & $32.38 \pm 2.56^{\star}$ \\
\hline \multirow[t]{2}{*}{ Morphine (mg/ml) } & 5 & $14.36 \pm 1.57$ & $41.29 \pm 3.98^{\star}$ & $69.65 \pm 4.82^{* *}$ & $41.98 \pm 4.53^{\star}$ & $36.31 \pm 3.87^{*}$ \\
\hline & 10 & $15.87 \pm 1.85$ & $43.46 \pm 3.73^{\star}$ & $68.06 \pm 4.77^{\star \star}$ & $45.14 \pm 4.28^{\star}$ & $39.08 \pm 3.86^{*}$ \\
\hline
\end{tabular}

Data are mean \pm SEM. ${ }^{\star} p<0.05 ;{ }^{\star *} p<0.01$ as compared with its saline group ( $n=6$ in each group). The antinociceptive effect was expressed in \% MPE.

120 hours induce pain in a duration-dependent manner in the land snails (Kavaliers et al. 1990). Likewise, a 48 h exposure to a $60 \mathrm{~Hz}$ EMF produces hyperalgesia in the light period in mice (Jeong et al. 2006). The inhibitory effects of EMFs on pain have been demonstrated by a number of different investigators in a variety of studies (Wolsko et al. 2004; Prato et al. 2005). Consistent with these findings, 15-30 min acute exposures to EMFs block the elevated pain responses in snails (Kavaliers et al. 1990). In the same way, our results suggest that three times for $30 \mathrm{~min}$ acute exposures to EMFs enhances the analgesic activity by TF and HP tests in rats.

Several studies have suggested that EMFs prevent morphine analgesic activity. This was observed in mice, rats, land snails and rodent (Del Seppia et al. 2007). There were also shown to be day-night variations in the levels of morphine-induced analgesia and the effects of EMFs, with maximum analgesia and inhibitory effects of EMFs evident at night. These analgesic effects have been associated with the day-night rhythm of opioid receptor numbers and binding characteristics. This suggests that the inhibitory effects of EMFs on reducing nocturnal basal nociceptive sensitivity may, at least in part, be associated with a reduction of endogenous opioid activity. It has been shown that 15-30 min exposures to rotating magnetic field $(0.1-0.8 \mathrm{mT} ; 0.5 \mathrm{~Hz})$ inhibited opioid analgesia (Kavaliers and Ossenkopp 1988). Furthermore, experimental studies reported that calcium channels involve in magnetic field inhibition of morphine analgesia (Kavalliers and Ossenkopp 1987).

The various studies on opioid receptors indicate that EMFs differentially suppressed the analgesia mediated by mu opioid peptide (MOP), delta opioid peptide (DOP), and kappa opioid peptide (KOP) receptors (Kavaliers and Ossenkopp 1986). Analgesia mediated by MOP and KOP receptors was further shown to be reduced in the snails (Kavaliers and Ossenkopp 1988). The suppressive effects of EMFs on DOP receptor-mediated antinociception were also shown in the land snails. In contrast to these studies, further research has discovered that exposures to magnetic field have positive pain relieving and analgesic effect. For example, Thomas et al. (1997b) suggest that 15-min exposures to an EMF $(100 \mu \mathrm{T})$ in land snails increased opioid analgesia rather than producing inhibitory effect. Magnetic field used for magnetic resonance imaging (MRI) reduces the nociception induced in mice by the MOP receptor agonists (Teskey et al. 1988). These evidences suggest that the possibility of a direct effect of EMFs on opioid receptor numbers or their functional activity. Consistently, an animal study indicated that 4-day magnetic exposure increased the levels of betaendorphin in the hypothalamus (Bao et al. 2006). In addition, our data demonstrate that the analgesic activity of morphine is significantly increased by the exposure EMF to the rats. It has been indicated that these findings may explain, in part, the analgesic effect of repeated exposures to EMFs.

The opioid analgesic tolerance involves associative and non-associative processes (Bailey and Connor 2005). In the non-associative view, opioid tolerance results from changes in underlying neurophysiological processes. This includes opioid receptor desensitization, down-regulation and the induction of endogenous anti-opioid receptor systems. Animal studies suggested that repeated acute EMF exposures attenuated the development of tolerance to morphine through in non-associative factors (Kavaliers and Ossenkopp 1985). Consistently, our findings demonstrated that the exposure magnetic field to the rats was decreased morphine antinociceptive tolerance. Besides, it has been indicated that opioid tolerance develops to the analgesic effects of pulsed magnetic field, with cross-tolerance to the analgesic actions of DOP receptor agonist in the land snail (Thomas et al. 1998). In this study, it has been found that the magnitude of the magnetic field-induced analgesia was 
reduced following repeated daily (15 or $30 \mathrm{~min}$ ) exposures: an effect indicative of the development of opioid tolerance. In addition, snails that received repeated daily exposures to the specific pulsed EMF $(100 \mu \mathrm{T})$ displayed decreased sensitivity of the DOP receptor agonist [D-Pen 2,5]-enkephalin hydrate (DPDPE). This decreased sensitivity provides evidence for the development of cross-tolerance of the DPDPE to the opioid component of pulsed EMF.

One of the mechanisms of the magnetic field on the morphine analgesia is to alter the cytokine levels. Exposure of rats to ELF-EMF decreased proinflammatory cytokine production (Salehi et al. 2013). Furthermore, chronic morphine administration activates spinal proinflammatory responses. These responses contribute to the inhibition of acute morphine analgesia and development of tolerance. In particular, proinflammatory cytokine IL- 1 is early signals in the recruitment of endogenous pain facilitatory mechanisms that modulate opioid analgesia (Fairbanks and Wilcox 2000). Therefore, the morphine tolerance can be attenuated by pretreatment with the IL-1 receptor antagonist or EMF.

In conclusions, this study indicated that the extremely low frequency electromagnetic fields have a significant effect on morphine analgesia and tolerance in analgesia tests. Application of the extremely low frequency EMF to rats increases the morphine analgesia and reduces morphine analgesic tolerance. Further research is required for clinical use of the electromagnetic fields.

Acknowledgement: This study was funded by Cumhuriyet University Scientific Research Project (T-329, CUBAP, Turkey).

Conflict of interest: The authors declare that they have no conflict of interest.

\section{References}

Altun A., Ozdemir E., Yildirim K., Gursoy S., Durmus N., Bagcivan I. (2015): The effects of endocannabinoid receptor agonist anandamide and antagonist rimonabant on opioid analgesia and tolerance in rats. Gen. Physiol. Biophys. 34, 433-440

Bailey C. P., Connor M. (2005): Opioids: cellular mechanisms of tolerance and physical dependence. Curr. Opin. Pharmacol. 5, 1-9 https://doi.org/10.1016/j.coph.2004.08.012

Bao X., Shi Y., Huo X., Song T. (2006): A possible involvement of beta-endorphin, substance $\mathrm{P}$, and serotonin in rat analgesia induced by extremely low frequency magnetic field. Bioelectromagnetics 27, 467-472 https://doi.org/10.1002/bem.20232

Bassett C. (1993): Beneficial effects of electromagnetic fields J. Cell. Biochem. 51, 387-393 https://doi.org/10.1002/jcb.2400510402

Chalidis B., Sachinis N., Assiotis A., Maccauro G. (2011): Stimulation of bone formation and fracture healing with pulsed elec- tromagnetic fields: Biologic responses and clinical implications. Int. J. Immunopathol. Pharmacol. 24, 17-20 https://doi.org/10.1177/03946320110241S204

Del Seppia C., Ghione S., Luschi P., Ossenkopp K.-P., Choleris E., Kavaliers M. (2007): Pain perception and electromagnetic fields. Neurosci. Biobehav. Rev. 31, 619-642 https://doi.org/10.1016/j.neubiorev.2007.01.003

Dumas E. O., Pollack G. M. (2008): Opioid tolerance development: a pharmacokinetic/pharmacodynamic perspective. AAPS J. 10, 537-551 https://doi.org/10.1208/s12248-008-9056-1

Fairbanks C. A., Wilcox G. L. (2000): Spinal plasticity of acute opioid tolerance. J. Biomed. Sci. 7, 200-212 https://doi.org/10.1007/BF02255467

Fernandez M. I., Watson P. J., Rowbotham D. J. (2007): Effect of pulsed magnetic field therapy on pain reported by human volunteers in a laboratory model of acute pain. Br. J. Anaesth. 99, 266-269 https://doi.org/10.1093/bja/aem129

Fields H. (2004): State-dependent opioid control of pain. Nat. Rev. Neurosci. 23, 7255-7261 https://doi.org/10.1038/nrn1431

Gursoy S., Ozdemir E., Bagcivan I., Altun A., Durmus N. (2011): Effects of alpha 2-adrenoceptor agonists dexmedetomidine and guanfacine on morphine analgesia and tolerance in rats. Ups. J. Med. Sci. 116, 238-246 https://doi.org/10.3109/03009734.2011.597889

Jeong J. H., Kum C., Choi H. J., Park E. S., Sohn U. D. (2006): Extremely low frequency magnetic field induces hyperalgesia in mice modulated by nitric oxide synthesis. Life Sci. 78, $1407-1412$ https://doi.org/10.1016/j.lfs.2005.07.006

Kanaan S. A., Saade N. E., Haddad J. J., Abdelnoor A. M., Atweh S. F., Jabbur S. J., Garabedian B. S. (1996): Endotoxin-induced local inflammation and hyperalgesia in rats, a new model for inflammatory pain. Pain 66, 373-379 https://doi.org/10.1016/0304-3959(96)03068-0

Kavaliers M., Ossenkopp K. P., Hirst M. (1984): Magnetic fields abolish the enhanced nocturnal analgesic response to morphine in mice. Physiol. Behav. 32, 261-264 https://doi.org/10.1016/0031-9384(84)90139-2

Kavaliers M., Ossenkopp K. P. (1985): Tolerance to morphineinduced analgesia in mice: magnetic fields function as environmental specific cues and reduce tolerance development. Life Sci. 37, 1125-1135 https://doi.org/10.1016/0024-3205(85)90356-X

Kavaliers M., Ossenkopp K. P. (1986): Magnetic fields differentially inhibit mu, delta, kappa and sigma opiate-induced analgesia in mice. Peptides 7, 449-453

https://doi.org/10.1016/0196-9781(86)90013-6

Kavalliers M., Ossenkopp K.-P. (1987): Calcium channel involvement in magnetic field inhibition of morphine-induced analgesia. Naunyn-Scheimedeberg's Archieves of Pharmacology 336, 308-315 https://doi.org/10.1007/BF00172683

Kavaliers M., Ossenkopp K. P. (1988): Magnetic field inhibit opioidmediated ,'analgesic" behaviors of the terrestrial snail (Cepaea nemoralis). J. Comp. Physiol. 162A, 551-558 
https://doi.org/10.1007/BF00612520

Kavaliers M., Ossenkopp K. P., Lipa S. M. (1990): Day-night rhythms in the inibitory effects of $60 \mathrm{~Hz}$ magnetic fields on opiate-mediated , analgesic' behaviors of the land snail, Cepaea nemoralis. Brain Res. 517, 276-282 https://doi.org/10.1016/0006-8993(90)91038-I

Kieffer B. L. (1999): Opioids: first lessons from knockout mice. Trends Pharmacol. Sci. 20, 19-26 https://doi.org/10.1016/S0165-6147(98)01279-6

Lee Y. J., Hyung K. E., Yoo J. S., Jang Y. W., Kim S. J., Lee D. I., Lee S. J., Park S. Y., Jeong J. H., Hwang K. W. (2016): Effects of exposure to extremely low-frequency electromagnetic fields on the differentiation of Th17 T cells and regulatory T cells. Gen. Physiol. Biophys. 35, 487-495 https://doi.org/10.4149/gpb_2016011

Morgan M. M., Christie M. J. (2011): Analysis of opioid efficacy, tolerance, addiction and dependence from cell culture to human. Br. J. Pharmacol. 164, 1322-1334 https://doi.org/10.1111/j.1476-5381.2011.01335.x

Nestler E. J., Aghajanian G. K. (1997): Molecular and cellular basis of addiction. Science 278, 58-63 https://doi.org/10.1126/science.278.5335.58

Ossenkopp K. P., Kavaliers M. (1988): Clinical and applied aspects of magnetic field exposure: possible role for the endogenous opioid systems. J. Bioelectricity 7, 189-208 https://doi.org/10.3109/15368378809027749

Ozdemir E., Bagcivan I., Gursoy S., Altun A., Durmus N. (2011): Effects of fluoxetine and LY 365265 on tolerance to the analgesic effect of morphine in rats. Acta Physiol. Hung. 98, 205-213 https://doi.org/10.1556/APhysiol.98.2011.2.12

Ozdemir E., Bağcivan I., Gursoy S. (2013): Role of D1/D2 dopamin receptors antagonist perphenazine in morphine analgesia and tolerance in rats. Bosn. J. Basic Med. Sci. 13, 1-7

Pesce M., Patruno A., Speranza L., Reale M. (2013): Extremely low frequency electromagnetic field and wound healing: implication of cytokines as biological mediators. Eur. Cytokine Netw. 24, $1-10$

Pilla A. A. (2013): Nonthermal electromagnetic fields: from first messenger to therapeutic applications. Electromagn. Biol. Med. 32, $123-136$ https://doi.org/10.3109/15368378.2013.776335

Prato F. S., Robertson J. A., Desjardins D., Hensel J., Thomas A. W. (2005): Daily repeated magnetic field shielding induces analgesia in CD-1 mice. Bioelectromagnetics 26, 109-117 https://doi.org/10.1002/bem.20056

Ramabadran K., Bansinath M., Turndorf H., Puig M. M. (1989): The hyperalgesic effect of naloxone is attenuated in streptozotocindiabetic mice. Psychopharmacology (Berl.) 97, 169-174 https://doi.org/10.1007/BF00442244

Ramey D. (1998): Magnetic and electromagnetic therapy. Sci. Rev. Altern. Med. 2, 13-19

Ross C., Harrison B. S. (2013): The use of magnetic field for the reduction of inflammation: A review of the history and therapeutic results. Altern. Ther. Health Med. 19, 47-54

Sadoghi P., Leithner A., Dorotka R., Vavken P. (2013): Effect of pulsed electromagnetic fields on the bioactivity of human osteoarthritic chondrocytes. Orthopedics 36, 360-365 https://doi.org/10.3928/01477447-20130222-27

Salehi I., Sani K. G., Zamani A. (2013): Exposure of rats to extremely low-frequency electromagnetic fields (ELF-EMF) alters cytokines production. Electromagn. Biol. Med. 32, 1-8 https://doi.org/10.3109/15368378.2012.692343

Sienkiewicz Z., Jones N., Bottomley A. (2005): Neurobehavioral effects of electromagnetic fields. Bioelectromagnetics 7, 116-126 https://doi.org/10.1002/bem.20141

Song P., Zhao Z. Q. (2001): The involvement of glial cells in the development of morphine tolerance. Neurosci. Res. (Suppl.) 39, 281-286 https://doi.org/10.1016/S0168-0102(00)00226-1

Sutbeyaz S., Sezer N., Koseoglu F., Kibar S. (2009): Low-frequency pulsed lectromagnetic field therapy in fibromyalgia: A randomized, double-blind, sham-controlled clinical study. Clin. J. Pain 25, 722-728 https://doi.org/10.1097/AJP.0b013e3181a68a6c

Teskey G. C., Prato F. S., Ossenkopp K.-P., Kavaliers M. (1988): Exposure to time varying magnetic fiels associated with magnetic resonance imaging reduces fentanyl-induced analgesia in mice. Bioelectromagnetics 9, 167-174 https://doi.org/10.1002/bem.2250090208

Thomas A. W., Kavaliers M., Prato F. S., Ossenkopp K.-P. (1997a): Antinociceptive effects of pulsed magnetic field in the land snails, Cepaea nemoralis. Neurosci. Lett. 222, 107-110 https://doi.org/10.1016/S0304-3940(97)13359-6

Thomas A. W., Kavaliers M., Prato F. S., Ossenkopp K.-P. (1997b): Pulsed magnetic field induced analgesia in the land snails, Cepaea nemoralis and the effects of $\mu$, $\mathrm{d}$, and $\kappa$ opioid receptor agonists/antagonists. Peptides 18, 703-709 https://doi.org/10.1016/S0196-9781(97)00004-1

Thomas A. W., Kavaliers M., Prato F. S., Ossenkopp K.-P. (1998): Analgesic effect of a specific pulsed magnetic field in the land snail (Cepaea nemoralis): consequences of repeated exposure, relations to tolerance and cross-tolerance with DPDPE. Peptides 19, 333-342 https://doi.org/10.1016/S0196-9781(97)00380-X

Traina G., Romanini L., Benazoo, F., Cadossi, V. (1998): Use of electric and magnetic stimulation in orthopaedics and traumatology: Consensus conference. J. Ortho. Trauma. 24, 1-31

Trock D. (2000): Electromagnetic fields and magnets: investigational treatment for musculoeskeletal disorders. Rheum. Dis. Clin. North. Am. 26, 51-62 https://doi.org/10.1016/S0889-857X(05)70119-8

Wolsko P. M., Eisenberg D. M., Simon L. S., Davis R. B., Walleczek J., Mayo-Smith M., Kaptchuk T. J., Phillips R. S. (2004): Double-blind placebo-controlled trial of static magnets for the treatment of osteoarthritis of the knee: results of a pilot study. Altern. Ther. Health Med. 10, 36-43

Zarrindast M. R., Dinkub Z., Homayoun H., Bakhtiarian A. (2002): Dopamine receptor mechanisms and morphine tolerance in mice. J. Pysychopharmacol. 16, 261-266 https://doi.org/10.1177/026988110201600312

Received: October 10, 2016

Final version accepted: February 13, 2017

First published online: August 24, 2017 